\title{
BPKIHS TB MODULE: AN INNOVATIVE WAY TO TEACH TUBERCULOSIS TO MEDICAL UNDERGRADUATES
}

\author{
Jha N, Yadav DK
}

School of Public Health \& Community Medicine, BPKIHS, Dharan

\begin{abstract}
Introduction: Tuberculosis is a major public health problem in Nepal. Medical schools need to practice evidence-based medicine for national TB control programmes. The objective of the study is to know the feedback about TB module from medical undergraduates.

Methodology: This is descriptive study designed to know the feedback regarding content and usefulness of TB teaching module from medical undergraduates of BP Koirala Institute of Health Sciences. The total duration of the study was from March 2004 to May 2008.

Results: The feedback about the TB teaching module was taken from 471 students. Out of them $64.7 \%$ (305) were males and $35.3 \%$ (166) females. Almost all students replied that objective of the module was clear and relevant. "TB teaching module is very useful" was the overall comments of the respondents particularly in respect of structured interactive session (SIS), Lecture, and Field visit to Primary Health Care Center, Britain Nepal Medical Trust, Nepal Anti Tuberculosis Association (NATA). Regarding the relevancy of the module, around $98 \%$ students' response was "relevant" and regarding the contents, $11 \%$ students' response was "content is too much".
\end{abstract}

Conclusion: It is recommended that this innovative BPKIHS TB module may be implemented in other medical schools of SAARC countries after necessary modifications in their own context.

Key words: Tuberculosis, Teaching module, Medical schools, Nepal

\section{INTRODUCTION}

Tuberculosis (TB) is a major public health problem in Nepal. Every year about 40,000 people develop tuberculosis; nearly half of them have infectious sputum positive tuberculosis and are capable of spreading the disease to others. ${ }^{1}$ It is estimated that around $45 \%$ of the country's population infected with TB. Introduction of Directly Observed Treatment

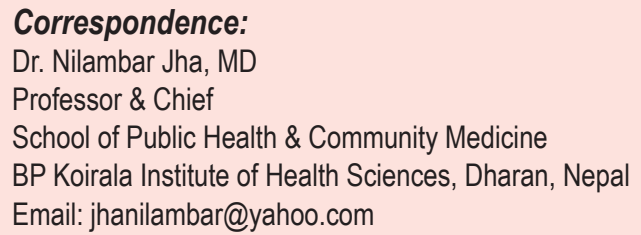

Short Course (DOTS) has already reduced the number of deaths. However, 6,000 to 7,000 people still die every year from this disease., ${ }^{1,2}$ DOTS, has been implemented throughout the country since April 2001. A key feature of DOTS in Nepal is the National TB Programme (NTP) partnership with organizations at the national, regional and local levels. ${ }^{2,3}$ Successfully implementing the DOTS strategy requires that doctors to be trained to manage TB properly. Obviously, the active participation of doctors in tuberculosis control will lead to a change in the attitude of other health care providers and their involvement will be achieved more easily. 4.5

Revised National TB Control Program (RNTCP) is implemented in India through the primary health 
care system; under the guidance of a MBBS passed medical officer (MO). ${ }^{6}$ Medical schools must adopt and use their potential to contribute proactively in shaping the future of the health system. By introducing changes in medical education, research and delivery of care for TB control, medical schools have the unique opportunity to demonstrate social accountability. Medical schools should provide every medical graduate with the knowledge, skills and attitudes essential to the management of TB in the patient and in the community as a whole. They should have an effective educational strategy to provide such ability to their students. ${ }^{4}$ Medical schools need to practice evidence-based medicine and thus contribute towards developing future guidelines for national control programmes. In order to improve their relevance, teaching medical institutions should redefine their mission statements and make essential modifications to unify teaching and practice. ${ }^{5}$

The BP Koirala Institute of Health Sciences at Dharan was the first institute in Nepal to set up a DOTS teaching centre. Concerted efforts have been made to orient training to the perceived needs of the community and to the principles of the national control programme. ${ }^{7}$ A major step to control tuberculosis is by providing assistance to the national programme in three main areas: Teaching, Service and Research.

Teaching Practices of BPKIHS: The MBBS curriculum of BPKIHS is thoroughly integrated and community oriented and partially problem-based, incorporating a need-based approach. During the first two years, emphasis is laid on the pre and para clinical sciences along with community medicine and professional skills; and in the next two and half years, the emphasis is on clinical sciences with a high degree of integration between clinical disciplines and community medicine; while the foundation of pre and Para clinical sciences continues to be strengthened. The curriculum incorporates early patient contact and emphasizes the importance of the study of community medicine and behavioral sciences from the beginning. Teaching through lectures has been restricted to a bare minimum while problem-based and handson learning experiences are encouraged. During the clinical posting, the students are regularly taken once a week to the District Health Office to orient them to the major local health problems and the various national health programs. In view of the seriousness of the problem of tuberculosis in Nepal, the Institute has developed a module on tuberculosis for teaching undergraduate students of medicine.

\section{BPKIHS, Teaching Module of Tuberculosis:} The module respects the need for imparting teaching in class, laboratory and field involving various teaching departments. The aim is to provide students with a broad and comprehensive knowledge of tuberculosis and especially to develop skills in diagnosis and management of the disease, in compliance with the National TB Control Program of Nepal.

\begin{tabular}{|l|l|l|}
\hline \multicolumn{4}{|l|}{ Table 1. BPKIHS, TB teaching module for medical undergraduates } \\
\hline Topics of Structured Interactive Session (SIS) & Department & Duration \\
\hline Magnitude of TB problem and national tuberculosis program. & Community Medicine & 1 hour \\
\hline Laboratory diagnosis of tuberculosis & Microbiology & 1 hour \\
\hline Pulmonary tuberculosis (Pathogenesis, clinical features, complications) & Medicine & 1 hour \\
\hline $\begin{array}{l}\text { Extra pulmonary tuberculosis (TB meningitis, Lymph node involvement, } \\
\text { pleural effusion) }\end{array}$ & Medicine & 1 hour \\
\hline Genital tract TB in females & Gynae/Obstetrics & 1 hour \\
\hline $\begin{array}{l}\text { Management of childhood tuberculosis and neonates born to mothers } \\
\text { suffering from TB }\end{array}$ & Paediatric & 1 hour \\
\hline $\begin{array}{l}\text { Treatment of tuberculosis including in special situations e.g. pregnancy, } \\
\text { renal failure, elderly, liver disease, etc. }\end{array}$ & Medicine & 1 hour \\
\hline Intestinal tuberculosis; abdominal tubercular lymphadenitis & Surgery & 1 hour \\
\hline Bone and joint TB including hip and knee joint TB & Orthopaedics & 1 hour \\
\hline Spinal tuberculosis including cold abscess & Orthopaedics & 1 hour \\
\hline Urogenital tuberculosis in males & Surgery & 1 hour \\
\hline TB with HIV \& emergencies in tuberculosis & Medicine & 1 hour \\
\hline Skin manifestations of TB & Dermatology & 1 hour \\
\hline
\end{tabular}




\begin{tabular}{|c|c|c|}
\hline Student's Seminar (SEM) & Department & Duration \\
\hline \multicolumn{3}{|l|}{ Tuberculosis with special reference to Nepal } \\
\hline $\begin{array}{l}\text { Epidemiology } \\
\text { National tuberculosis control programme } \\
\text { Multi-drug resistance tuberculosis } \\
\text { New advance in the diagnosis and management } \\
\text { Prevention of tuberculosis }\end{array}$ & $\begin{array}{l}\text { Community Medicine, } \\
\text { Medicine, Surgery, } \\
\text { Paediatrics, Gyne/Obs, } \\
\text { Pharmacology }\end{array}$ & 2 hours \\
\hline \multicolumn{3}{|l|}{ Small Group Discussion (SGD) } \\
\hline X-ray & Radiology(batch wise) & 2 hours for each batch \\
\hline \multicolumn{3}{|l|}{ LABEX } \\
\hline ZN staining and Mantoux-testing & $\begin{array}{l}\text { Microbiology(batch } \\
\text { wise) }\end{array}$ & 2 hours for each batch \\
\hline \multicolumn{3}{|l|}{ Slide Session } \\
\hline $\begin{array}{l}\text { Gross and microscopic lesions in tuberculosis of various } \\
\text { organs }\end{array}$ & Pathology & 2 hours for each batch \\
\hline \multicolumn{3}{|l|}{ Case Based Learning in Field (CBLF) } \\
\hline $\begin{array}{l}\text { Visit to NGO (Britain Nepal Medical Trust, Nepal Anti } \\
\text { Tuberculosis Association) } \\
\text { Visit to Madhuban/lthari - DOTS clinic }\end{array}$ & $\begin{array}{l}\text { Community Medicine } \\
\text { Community Medicine }\end{array}$ & $\begin{array}{l}1 \text { day } \\
1 \text { day }\end{array}$ \\
\hline \multicolumn{3}{|l|}{ Case Based Learning (CBL) } \\
\hline Hospital Indoor (Wards) & $\begin{array}{l}\text { Medicine, Paediatrics, } \\
\text { Surgery (batch wise) }\end{array}$ & 2 hours for each batch \\
\hline
\end{tabular}

During Phase I (first two years of MBBS course); TB is taught as Problem Based Learning (PBL) duration of one Week and major departments involved in this program are Community Medicine, Medicine, Microbiology, Pathology, and Pharmacology. In phase II (next two and half years), over 13 hours of structured interactive sessions, are conducted by various departments (Table $1 \&$ Table 2 ) in addition to those, seminars and small group teachings activities were in third year of MBBS course. The Case Based Learning in Field (CBLF), visit to NGO (Britain Nepal Medical Trust, Nepal Anti Tuberculosis Association), Primary Health centre DOTS program was conducted by the department of Community Medicine. Case Based Learning (CBL) in hospital Wards of Medicine, Pediatrics' \& Surgery departments were also done in different batches. To know the feedback about BPKIHS TB Module from $3^{\text {rd }}$ year medical undergraduates.

\section{METHODOLOGY}

A descriptive study was applied for the study over period from March 2004 to May 2008. The study was conducted by the department of Community Medicine, BP Koirala Institute of health sciences. Feedbacks were taken from $3^{\text {rd }}$ year MBBS students of the batches from 2004 to 2008, who had gone through teaching method of TB Module. Semi structured questionnaire was used to perform interview applying convenience sampling technique. The key data information included different characteristics of TB module like content, relevancy, objective, student participation, time adequacy and some suggestion to improvement.

The collected data were entered into computer using excel data sheet. The qualitative data were summarized and expressed as frequency, percentage and presented in tables, bar diagram and pie chart.

\section{RESULTS}

A total of 471 students participated in the study (Table 3). The distribution of student's number was different from 2004 to 2008. Male students were found more than females. 


\begin{tabular}{|c|c|c|c|}
\hline Year & \begin{tabular}{|l} 
Male \\
(row \%)
\end{tabular} & $\begin{array}{l}\text { Female } \\
\text { (row \%) }\end{array}$ & Total \\
\hline 2004 & 47 (62.7\%) & $28(37.3)$ & 75 \\
\hline 2005 & $66(66.0 \%)$ & $34(34.0 \%)$ & 100 \\
\hline 2006 & $65(67.7 \%)$ & $31(32.3 \%)$ & 96 \\
\hline 2007 & $62(62.0 \%)$ & $38(38.0 \%)$ & 100 \\
\hline 2008 & \begin{tabular}{|l}
$65(65.0 \%)$ \\
\end{tabular} & $35(35.0 \%)$ & 100 \\
\hline Total & $305(64.7 \%)$ & 166 (35.3\%) & $471(100 \%)$ \\
\hline
\end{tabular}

In the present study $87.2 \%$ students told that contents of TB was adequate (Table 4). Most $(82.7 \%)$ of the students said that student's participation during teaching TB module was enough. Majority $(89.2 \%)$ of them replied that time allotted for teaching module was adequate.

\begin{tabular}{|c|c|c|c|c|}
\hline Characteristics & Adequate & \begin{tabular}{|c|} 
Too \\
much
\end{tabular} & Inadequate & Total \\
\hline $\begin{array}{l}\text { Content of the } \\
\text { Module }\end{array}$ & $87.2 \%$ & $11.4 \%$ & $1.4 \%$ & $100 \%$ \\
\hline $\begin{array}{l}\text { Students } \\
\text { participation }\end{array}$ & $82.7 \%$ & $0 \%$ & $17.3 \%$ & $100 \%$ \\
\hline Time allotted & $89.2 \%$ & $9.1 \%$ & $1.7 \%$ & $100 \%$ \\
\hline
\end{tabular}

Regarding objective of the module, almost all students replied that that objective of the TB module was clear,

A significant positive response was found among the students $(97.5 \%)$ related to relevancy of the contents of the TB module (Figure 1).

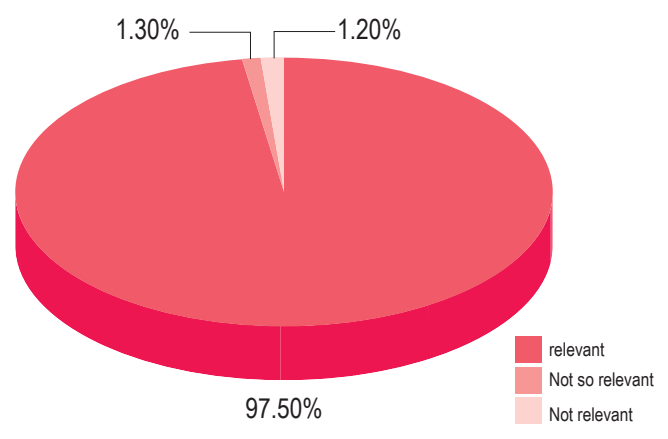

Figure 1. Relevancy of the contents of TB module

Majority of the students (97-98\%) appreciated the field visits to PHC DOTS program and NGO/ INGO supported DOTS clinics (BNMT, NATA). They found these field visits very useful \& informative. Similarly $98.4 \%$ students reported that the methodologies used for different activities and sessions in TB modules were. (Structured, interactive sessions, Lectures, Seminar) appropriate and very useful for them (Figure 2)

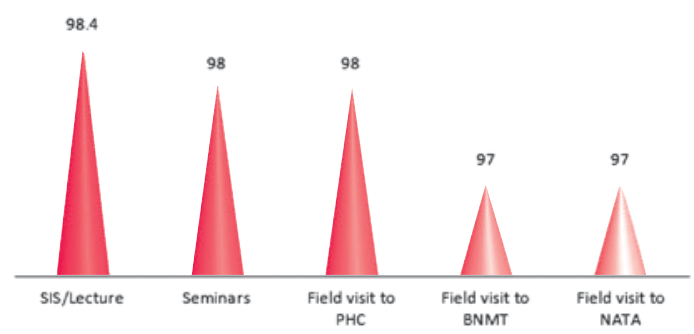

Figure 2. Responses of different teaching methods used in TB module

\section{DISCUSSION}

The BPKIHS TB module, is thoroughly integrated, community oriented, field based and case-based, incorporating a need -based approach. The module was well received by medical undergraduates. Almost all reported that the objective of TB module was clear. Regarding content and relevant of the module around $98 \%$ replied that it was relevant where as $11 \%$ said "its contents are too much". Nearly Ninety eight percent $(97.5 \%)$ replied that TB module was relevant with TB diagnosis and treatment. Duration of the TB module was reported to be adequate by majority ( $89.2 \%$ ) students where as few $(1.7 \%)$ opined as inadequate.

Student's knowledge, based on assessments, increased to satisfactory levels. A study by $\mathrm{N}$ Selvakumar et al, Proficiency to read sputum AFB smears by senior tuberculosis laboratory supervisors under training at reference laboratory, the sensitivity to read sputum AFB smear by fresh trainee with little or no experiences increased from $75 \%$ to $94 \%$ during the carefully planned training programme; the specificity increased from $88 \%$ to $99 \%{ }^{8}$

Almost all (98\%) students felt that field visits were very useful \& informative; health workers in NATA and primary health center (PHC) were helpful and gave opportunity to learn in friendly environment. Such field visits help to understand the real scenario of care providers and problems faced by them during diagnosis \& treatment. 
Regarding methodology for the module, they replied that it was appropriate and useful (98.4\%). The novel aspects of teaching included reading chapters in classroom followed by Problem Based Learning (PBL) \& seminar, modular assessments were highly rated.

Similar result was found in the study done by Harries AD et al, the Malawi experience, teaching tuberculosis control to medical undergraduates by using the teaching module from $2000-2002 .^{9}$

Suggestions provided by students: The student's suggestions were that the module should include management of MDR and XDR TB, as well as $B C G$ vaccination. Interaction with TB patients should be encouraged during the field visits. Student's participation should be increased as much as possible. The module should have more practical aspects. Similar type of teaching module should be developed for other disease like Malaria, Kalaazar and HIVIAIDS.

\section{CONCLUSION}

The module was well received and appreciated by the undergraduate medical students. It is recommended that this innovative BPKHIS TB module may be implemented in other medical school of SAARC countries after necessary modifications in their own context.

\section{REFERENCES}

1. National Tuberculosis Program of Nepal, a clinical manual, NTC third edition 2009.

2. Department of Health Services, MOH, Nepal, Annual report, 2005/2006.

3. WHO publication 2005, Regional Office for SouthEast Asia New Delhi, Tuberculosis control in the South East Asia region, The Regional Report, November 2005, WHO project no. ICP TUB 001: $1-2$.

4. JP Narain and LM Nath. The Role of Medical Schools in Tuberculosis Control in SK Sharma and A Mohan edt Tuberculosis. Jaypee Brothers Medical Publication (P) LTD. New Delhi. First Edition 2001;597-600.

5. WHO, Regional Office for South-East Asia, New Delhi. Enhancing the role of medical school in STD/HIV and TB control 2000:1.

6. Central TB Division (CTD), Directorate General of Health Services, Ministry of health and Family Welfare, Gov of India. Revised National TB Control Program. Technical guidelines for TB Control. New Delhi: CTD, 1997.

7. Jha N, Rijal S, Koirala S. Role of Medical school in TB control; An Experience from Nepal: Regional Health forum, WHO South East-Asia 2003;7

8. Selvakumar N, Kumar V, PG Gopi et al. Proficiency to read sputum AFB smears by senior tuberculosis laboratory supervisors under training at a reference laboratoty in India: Indian J Tuberc 2005;52:11.

9. Harries AD, Kumwenda J, Zijlstra EE et al. Teaching tuberculosis control to medical undergraduates: the Malawi experience. Int. J. Tuberc Lung Dis. 2003; $7: 842$ 